\title{
CUIDADO DO SER EM FREIRE: DIMENSÃO ONTOLÓGICA DO SER MAIS NA EDUCAÇÃO
}

\author{
Cláudia Soave ${ }^{24}$ \\ Simone Côrte Real Barbieri ${ }^{25}$ \\ Geraldo Antonio da Rosa ${ }^{26}$
}

\section{Resumo}

Este artigo tem por objetivo compreender a concepção da dimensão ontológica freireana pensada a partir de algumas relações da constituição subjetiva: primeiramente em sua relação com o cuidado do ser; e, posteriormente, como vocação ontológica do ser mais. A partir da obra Pedagogia da Autonomia foi possível identificar e interpretar as inter-relações presentes entre o cuidado do ser e sua dimensão ética. Transitando pela leitura exploratória das obras do autor Pedagogia do Oprimido, Educação como Prática da Liberdade e Ação Cultural para a Liberdade, percebemos a educação como condição necessária para o homem que se transforma, por sua ação reflexiva, e que quer vir a ser mais. Finalizaremos discutindo a educação como condição necessária para oportunizar a superação de uma posição passiva do estar objeto para uma postura de ser, responsável por sua própria existência.

Palavras-chave: Educação, cuidado do ser, vocação ontológica e ética.

\section{INTRODUÇÃO}

Diante da provocação de ler e explorar algumas obras do autor para poder exercitar um processo de escrita reflexiva, buscamos fazer escapes, relações, considerações e até mesmo alguns deslocamentos sobre as práticas e os discursos pedagógicos que são alvo do nosso escopo de pesquisa. Nosso primeiro desafio foi buscar uma interlocução com o autor, nosso segundo desafio foi descolar do pensamento de Freire para problematizar a educação na contemporaneidade. Esse foi o nosso principal sentimento: Freire não é um autor a se desconsiderar quando falamos em educação, entretanto, também precisa ser pensado dentro de

\footnotetext{
24 Doutoranda em Educação na Universidade de Caxias do Sul (PPGEDU/UCS) - Linha de Pesquisa História e Filosofia da Educação - Bolsista CAPES/PROSUC - Professora área de Gestão, contemplada com fomento interno para afastamento, no Instituto Federal de Educação, Ciência e Tecnologia do Rio Grande do Sul (IFRS) - Campus Bento Gonçalves. E-mail: claudia.soave@bento.ifrs.edu.br.

25 Doutoranda em Educação na Universidade de Caxias do Sul (PPGEDU/UCS) - Linha de Pesquisa História e Filosofia da Educação - Professora - Área do Conhecimento de Humanidades - Universidade de Caxias do Sul Campus Universitário da Região dos Vinhedos. E-mail: scrbarbi@ucs.br.

${ }^{26}$ Doutor em Teologia, Mestre em Educação - Professor do Programa de Pós Graduação em Educação (PPGEDU) e de Graduação na Área do Conhecimento de Humanidades, na Universidade de Caxias do Sul (PPGEDU/UCS). E-mail: garosa6@ucs.br
} 
nosso contexto de inserção e nas relações que nos atravessam e que projetamos a partir do nosso fazer pedagógico e de pesquisa.

Entendemos a importância acerca da diferença entre estar professor e ser professor. O estar no sentido de uma condição transitória que não gera comprometimento com causas e finalidades, ou seja, um trânsito sem construção, efêmero, que se esvai. Ao contrário do ser que não se separa da condição da busca constante pelo aperfeiçoamento, pela constituição permanente, infinita.

Nesse sentido, nossa problemática versa sobre: Qual o sentido ontológico da educação, pautado por Freire, e sua interface com o cuidado do ser e da dimensão ética presente na relação existente entre educadores e educandos? Relação configurada no movimento da natureza do ser de ser mais, como vocação existencial, desse ser de incompletude que se experiencia em processo de vir a ser. O objetivo geral é compreender a concepção da dimensão de ontologia freireana e sua relação com o cuidado do ser e do ser mais. Os objetivos específicos desdobram-se em identificar a noção de cuidado do ser, entender o sentido ético estabelecido entre educador e educando, e problematizar a experiência de constituição humana dentro dessa dimensão ontológica (ontológicafreireana) ${ }^{27}$ de se cuidar, se fazer, e ser mais.

De caráter exploratório, esta descrição e análise decorrem da interpretação da noção filosófica da ontologia em Freire e de sua conexão ao sentido do cuidado do ser, presente na obra Pedagogia da Autonomia. A escolha deriva do fato de considerarmos a autonomia inseparável da dimensão ontológica.

\section{DIMENSÃO DA ONTOLOGIA EM FREIRE}

$\mathrm{Na}$ concepção de mundo está implícita a concepção de ser e uma teoria do conhecimento, ou seja, uma ontologia e uma epistemologia. Em Freire não seria diferente, há uma teoria acerca de tudo que existe e sobre a forma de conhecer o que existe; a diferença está na distinção dessa ontologia. Enquanto na filosofia tradicional entende-se que a inteligência e a vontade de ser livre é que tornam o homem diferente dos demais seres vivos,

\footnotetext{
${ }^{27}$ Ao tomarmos a ideia de perspectiva ontológica freireana em uma expressão única queremos nos referir ao movimento identificado nos estudos de suas obras referente ao fato de que a experiência humana de constituição é um processo de autoedificação que não se dá de forma vertical e sim como horizonte com o qual o ser humano se relaciona em uma diversidade de possibilidades e vivências.
} 
segundo Freire a principal distinção do ser humano é a consciência sobre sua incompletude ${ }^{28}$. (ROMÃO, 2010)

Para Freire o ser humano, ao contrário dos animais, tem consciência do seu inacabamento e possui uma vocação ontológica do vir a ser mais $^{29}$. Essa característica é inerente, faz parte de sua função cultural, histórica e de ação junto à natureza. O ser aprende e ensina com os outros, com a natureza, com o Criador, ou seja, é um ser social, que possui disposição para a integração. Sendo assim, o ser humano é o único ser pedagógico que passa por um processo de constituição durante a sua existência.

Diante disso, a humanização do ser é um processo ontológico e educativo, que possibilitará a constituição individual, cultural, histórica e social. O ser não é estar, por isso tem as condições de passar da consciência ingênua para crítica. Nesse sentido "[...] não estou no mundo, eu sou no mundo[...]" (FREIRE, 2005, p. 53).

Tomaremos aqui a distinção entre ser no mundo e estar no mundo pela perspectiva Heideggeriana, que se apresenta discutida nos diferentes modos de existência humana através do conceito de Dasein:

O Dasein partilha com os outros o espaço que circunda. Em sua ocupação ele se encontra a si mesmo e aos outros. De fato, nesta possibilidade de ser-com-os-outros, "o estar-só do Dasein é ser-com no mundo (...). O próprio Dasein só é na medida em que possui a estrutura essencial de ser-com, enquanto co-Dasein que vem ao encontro dos outros. (HEIDEGGER, 1998, p. 171)

O ser que é visto no mundo a partir dessa abordagem clássica existencialista, é com o mundo que ele habita em determinados contextos, com determinadas condições e relações historicamente situado, capaz de compreender as influências que exerce e sob as quais está sujeito, e reconstituir significados e valores de acordo com esse tempo e espaço de seu contexto espaço-temporal. Heiddeger usa o termo dasein, que pode ser pensando como o ser aí, aquele que está em algum lugar, mas que só é por estar referenciado historicamente e aberto às relações com esse mundo em que ele se encontra. Um ser em situação, que compõe as condições não do lugar onde ele existe, mas sim de seu modo de existir. Em dissonância com o ser que está no mundo jogado na condição de coisa, mais um elemento de uma

\footnotetext{
${ }^{28}$ Romão (2010) destaca que Freire usa o termo inacabado como sinônimo de incompleto e inconcluso. Entretanto, há uma distinção entre os três. Os seres vivos são incompletos pois necessitam uns dos outros, inconclusos devido à ideia de evolução e inacabados no sentido de imperfeitos.

${ }^{29}$ Trombetta e Trombetta (2010) destacam o caráter da vocação ontológica humana para o ser mais, na qual o destino do ser é criar, transformar o mundo enquanto sujeito ativo e não mero objeto passivo, nesse caso uma educação humanista libertadora é que oportuniza ao aprimoramento humano.
} 
diversidade da qual participa de forma passiva e determinada pelas condições sob as quais fica submetido.

O estar, nesse aspecto, seria a determinação a não assumir a condição de ser, renegando a condição do ser mais e deixando a outrem ocupar o próprio lugar, não assumindo a posição de "ser" nesse lugar (planeta/mundo), ou seja, o destino não é um estado, ele é feito pela ação humana no tempo, nas relações. "Gosto de ser gente porque a História em que me faço com os outros e de cuja feitura tomo parte é um tempo de possibilidades e não de determinismo." (FREIRE, 2005, p. 53).

Nesse contex to a desumanização decorre quando se anula esse direito ao ser e ao vir a ser mais, ou seja, quando ao ser humano é assegurado apenas o estar determinado a ser aquilo que é esperado que ele seja. Por isso não há como separar o ser de sua essência ao devir. Um exemplo é em relação ao conteúdo, enquanto aprendo e apreendo sobre um conteúdo também aprendo e apreendo algo a mais de mim e sobre mim e sobre o mundo, me transformo, mesmo que condicionado. "Gosto de ser gente porque, inacabado, sei que sou um ser condicionado mas, consciente do inacabamento, sei que posso ir além dele.” (FREIRE, 2005, p. 53).

Ao perceber e assumir sua posição em relação a si, aos outros e com o mundo o homem está exercendo sua vocação ontológica a participar ativamente, a intervir junto ao mundo. (FREIRE, 2005, p. 54). Uma posição ativa, de busca constante, de quem luta como sujeito e não se deixa apenas conduzir como um objeto. Um constante movimento de aprender e apreender.

Mulheres e homens, somos os únicos seres que, social e historicamente, nos tornamos capazes de apreender. Por isso, somos os únicos em quem aprender é uma aventura criadora, algo, por si mesmo, muito mais rico do que meramente repetir a lição dada. Aprender para nós é construir, reconstruir, constatar para mudar, o que não se faz sem abertura ao risco e à aventura do espírito. (FREIRE, 2005, p. 69).

Essa condição do ser de constituir-se integrando-se ao mundo e operando mudanças é peculiar à natureza humana. E essa relação com o ser em contínuo movimento de busca tem conexão com outros aspectos ontológicos que Freire toma enquanto parte da ontologia, dentre eles: (1) a esperança, (2) a curiosidade, (3) a autonomia e a (4) a ética.

A esperança é o combustível que torna o homem capaz de enfrentar o condicionamento a que está submetido, mas não determinado. Freire considera que a esperança é intrínseca à natureza humana, ela é que acrescenta o sabor para que se que possa 
continuar a busca, tendo em vista a incompletude do homem, a "esperança é um condimento indispensável à experiência histórica. Sem ela não haveria História, mas puro determinismo." (FREIRE, 2005, p. 72). Além disso, a alegria no contexto da prática docente é companheira da esperança, é ela que alimenta a resistência aos desafios.

Diferente do animal, que nasce determinado e sem condições de projetar sua história e reflexão no tempo e espaço, o homem possui essa disposição interior que o faz acreditar e lutar pela possibilidade de mudança frente às injustiças, face à realidade com a qual discorda ou a que está condicionado, o que demonstra que a utopia caminha ao lado da esperança. Sem utopia e sem essa confiança, sonhos não seriam possíveis. A utopia em Freire é também esperança de concretização de sonhos possíveis e da capacidade de transformação, é "uma necessidade ontológica" (FREITAS, 2010, p. 412).

Já a curiosidade é a propulsão, o fomento, um direito humano, levando em conta os limites dentro de um ambiente pedagógico-democrático. O aprendizado real provém do exercício da curiosidade. Entretanto, Freire ressalta o caráter epistemológico dessa curiosidade, que nasce da curiosidade espontânea, mas se aprimora à medida que houver maior aproximação e aprofundamento em relação a um objeto de estudo. Sem essa abertura dada pela curiosidade não seria possível a transição para a consciência. (FREIRE, 2005, p. 84 a 90). A curiosidade é o elemento impulsionador do ser humano, enquanto a curiosidade epistemológica é a curiosidade científica sempre presente no processo educativo libertador, que inquieta parte da curiosidade ingênua. (VASCONCELLOS; BRITO, 2014).

A autonomia por sua vez é outra condição inerente ao homem e mulher, decorrente de um processo de amadurecimento, relacionado à tomada de decisão individual e a apropriação das responsabilidades. (VASCONCELLOS; BRITO, 2014).

Nesse sentido, sublinhamos aqui a relação que Freire faz do exercício da autonomia enquanto respeito à condição humana de um ser, que inacabado, tem direito à dignidade da apropriação de si, de sua formação e direito à passagem para a consciência crítica ao longo de sua existência.

A ética em Freire revela-se como um princípio universal de reconhecimento, amor e respeito ao outro e a seus princípios e diferenças. "A ética de que falo é a que se sabe traída e negada nos comportamentos grosseiramente imorais como na perversão hipócrita da pureza em puritanismo. A ética de que falo é a que se sabe afrontada na manifestação discriminatória da raça, de gênero, de classe." (FREIRE, 2005, p. 16).

Para Freire desrespeitar a natureza humana do educando em sua incompletude tolhendo a curiosidade, a inquietude, seu gosto estético, sua linguagem, bem como deixar de 
propor limites, tendo o cuidado necessário para não ser autoritário, transgride os princípios fundamentalmente éticos da existência humana. Essa transgressão está relacionada a não oprimir, a respeitar a autonomia de cada um.

\begin{abstract}
A autonomia, enquanto amadurecimento do ser para si, é processo, é vir a ser. Não ocorre em data marcada. É neste sentido que uma pedagogia da autonomia tem de estar centrada em experiências estimuladoras da decisão e da responsabilidade, vale dizer, em experiências respeitosas da liberdade. (FREIRE, 2005, p. 107).
\end{abstract}

Nesse contexto, frisamos a importância dada por Freire à condição do ser humano e a sua incompletude, aliada à necessidade do educador buscar essa compreensão de dimensão ontológica. Esta, por sua vez possibilita uma busca incessante pelo conhecimento teórico aliado à compreensão das características essenciais em respeito à constituição e formação do ser, evidenciando que a educação não se separa do cuidado do ser e de sua dimensão ética.

\title{
3 O CUIDADO DO SER E DO SER MAIS: POSSÍVEIS PERSPECTIVAS PARA SE PENSAR A EDUCAÇÃO
}

A dimensão ontológica em Freire conduz a algumas questões. Existe a possibilidade de separar a educação do cuidado do ser e do ser mais? A Educação prepara para a vida ou para o trabalho? A Educação é um processo que visa ao preparo para a competição, pregada por uma concepção neoliberal, ou para a constituição de um ser crítico, com possibilidades de reflexionar sobre si, sua cultura, sua história para poder se transformar e transformar o mundo em um lugar melhor para todos?

Parece haver um princípio gerador da ontologia em Freire que parte da consciência sobre a incompletude do ser, presente em cada um, e a necessidade de um processo educacional, que abra possibilidades de sair de um estado ingênuo e submisso a outro crítico e libertador. Ou seja, há uma condição interna que impulsiona o humano a vir-a-ser mais, a se modificar e transformar-se, em benefício coletivo. Tal condição é despertada pela curiosidade, a princípio ingênua, para um processo epistemológico e crítico, estimulado por uma pedagogia mais humana e progressista que se nega à prática da educação bancária, focada no adestramento do ser em prol de interesses mercadológicos apenas.

Nessa passagem de uma condição ingênua para uma crítica, há todo o cuidado para que cada ser humano possa exercer sua autonomia, mesmo diante das inúmeras formas de 
condicionamento a que está submetido. Porém, permitir que práticas de imposição e autoritarismo determinem o ser é para Freire um processo de desumanização, pois acaba com o reconhecimento do ser do outro, bem como desrespeita a condição vital para a formação humana e cidadã.

Estar longe, ou pior, fora da ética, entre nós, mulheres e homens, é uma transgressão. É por isso que transformar a experiência educativa em puro treinamento técnico é amesquinhar o que já de fundamentalmente humano no exercício educativo: o seu caráter formador. Se se respeita a natureza do ser humano, o ensino dos conteúdos não pode dar-se alheio à formação moral do educando." (FREIRE, 2005, p. 33)

Há uma determinação baseada em um capitalismo neoliberal que estimula o treino técnico em detrimento da formação humana, desonrando a presença humana e ética, modificada para sombra. (FREIRE, 2005, p. 102). Ao que Freire se contrapõe com uma ética universal do ser humano, ética da solidariedade humana, como forma de enfrentamento à exploração e ganância desempenhadas pelo lucro a qualquer preço. (2005, p. 129)

O cuidado do ser nesse contexto é o zelo pelos aspectos ontológicos intrínsecos a cada homem e mulher, que se liga à concepção de ética freireana, isto é, não se pode apenas "estar no mundo" mas "estar sendo" no mundo, agindo, participando, transformando. "Mulheres e homens, seres históricos-sociais, nos tornamos capazes de comparar, de valorar, de intervir, de escolher, de decidir, de romper, por tudo isso, nos fizemos seres éticos. Só somos porque estamos sendo. Estar sendo é a condição, entre nós, para ser.” (FREIRE, 2005, p. 33)

Portanto, o cuidado do ser é um princípio ético que se funda na experiência, durante a existência, e não a priori. A condição a priori do ser humano é o seu inacabamento e também as múltiplas possibilidades de vir-a-ser e não apenas de estar fixo, determinado no mundo. Desrespeitar ou não reconhecer essas características ontológicas é ferir a dimensão ética. Diante desse sentido de cuidado do ser, Freire propõe que "a capacitação de mulheres e homens em torno de saberes instrumentais jamais pode prescindir se sua formação ética" (2005, p. 56). Evidencia-se a proposta de liberdade a que cada ser humano tem direito, no sentido de exercer sua autonomia e constituir-se a si mesmo por meio da consciência crítica e da responsabilidade por sua existência, bem como pela relação com os demais seres e pela transformação histórica e cultural.

O legado deixado por Freire, expande as interpretações, bem como permite aproximar o pensamento de sua pedagogia ao contexto atual, tendo em vista que a dimensão ontológica e 
ética não se separa da prática docente e requer atenção especial, uma vez que a educação acontece com seres humanos e entre seres humanos, num contínuo processo de aprender e ensinar.

Como refletia o pensador, dentro das concepções que se relacionam ao cuidado do ser há a "impossibilidade de desunir o ensino dos conteúdos da formação ética dos educandos. De separar prática de teoria, autoridade de liberdade, ignorância de saber, respeito ao professor de respeito aos alunos, ensinar de aprender.” (FREIRE, 2005, p. 95). Não há como conceber a educação sem considerar a inter-relação presente entre educador e educando e a relação com a ontologia freireana, pois a formação humana depende do processo educativo em movimento contínuo do cuidado do ser.

Ao educador cabe a tarefa de conhecer a fundo um dos saberes indispensáveis à sua atuação "ensinar não é transferir conhecimento, mas criar as possibilidades para sua produção ou a sua construção.” (FREIRE, 2005, p. 22). Aqui se encontram uma das aberturas fundamentais para compreender o significado e a relevância da dimensão ontológica do cuidado do ser no pensamento de Paulo Freire.

O exercício da docência é social e ético. Se o ser humano nasce inacabado é no processo de relacionar-se que esse espaço se abre para novas transformações, e nesse sentido uma educação focada apenas na transferência de conhecimento impede a reflexão, a crítica e o ato de formar-se. Educadores e educandos são sujeitos ativos na formação de si e na construção do conhecimento, por isso não há docência sem discência, o ser em construção necessita aprender constantemente, caso contrário estaria determinado a apenas estar no mundo, sem ocupar uma posição de agir no mundo e contribuir para uma sociedade melhor.

Se aprender e ensinar são especificidades humanas, então, o cuidado do ser está ligado ao um contínuo desabrochar que se orienta pelas relações consigo mesmo, com ou outro, com o mundo e com os conteúdos.

Pela dimensão ontológica freireana que parte da incompletude humana, existe a prédisposição humana da curiosidade ingênua, que não deve ser desprezada pelo educador, despertando para a curiosidade epistemológica. A educação é a energia vital que nutrirá e permitirá a busca pela autonomia e, consequentemente a relação com essa vertente ética acerca do cuidado do ser.

\section{CONCLUSÕES}

O homem não é um ser de acomodação e sim um ser de cultura, a medida em que se relaciona e se percebe historicamente referenciado. Não é possível ficar passivo quando se 
coloca na relação com o mundo. Um ser de relações projeta, percebe, recebe, critica, se relaciona, ou seja, interage e interfere. De acordo com Freire, as capacidades de interferência e de ação são próprias da natureza humana, de modo que esse homem-sujeito: (1) é necessariamente um agente político em sua experiência social; (2) persegue a liberdade como espaço da experiência crítica; (3) estando historicamente implicado não se limita ao momento presente e pode, portanto, fazer a crítica e projetar a mudança como parte de suas relações.

O que significa considerar a possibilidade do ser mais como uma consequência das ações do homem que precisa se colocar na posição de protagonista de sua experiência, e considerando a educação condição necessária para que possa desenvolver seu processo de autoedificação. Por este motivo o aprendizado passa a ter um protagonismo no desenvolvimento das condições subjetivas. O homem aprende com, no, através de, em relação $a$. E o faz para poder ser livre. A preponderância da relação dialógica como condição necessária de possibilidade da educação que não pode ser transmitida nem dada, se constrói como ação do homem em seus processos de subjetivação, para estar a serviço de sua libertação e humanização.

O grande desafio da educação, de acordo com o autor, é conduzir da ingenuidade à criticidade. Pretende também confrontar a intransitividade ingênua que se fundamenta na pseudo-crítica dos que acreditam ter consciência das amarras e ter conseguido fazer um movimento de libertação. Mas que na verdade ficam mais firmemente acomodados por acreditar que se libertaram para apenas se aprisionar na objetificação e coisificação cultural e mercadológica. Para só então legitimar a crítica como movimento para viabilizar os processos de subjetivação humanos através da educação.

O que estamos tentando estabelecer aqui é esse lugar do homem que ao cuidar do ser, se percebe perplexo diante de sua própria incompletude e precisa ser mais para constituir sua autonomia e experiência de liberdade. Face à perspectiva ingênua que permeia os tempos, a educação no contexto atual, mais do que nunca, precisa trazer para discussão elementos da dimensão política, uma vez que ao invés dos avanços esperados estamos sendo atingidos por retrocessos e pela onda neoconservadora planetária de uma educação para a neutralidade e para a padronização.

De fato, a pretensão de neutralidade da educação nada mais representa do que uma acomodação ideológica em nome da manutenção das condições de dominação e desigualdade social. Cada vez que pretendemos dissociar a educação de sua essência política estamos orientados para o desenvolvimento de atividades e competências necessárias para o sucesso do sujeito que é medido pela sua utilidade para o funcionamento social. 
Por outro lado, para considerar a formação do sujeito como processo de autoedificação, não é possível dissociar a educação de sua essência política. Ou seja, a neutralidade não é pretendida nem é viabilizadora da transformação. O sujeito que precisa ser colocado na condição de agente responsável e aprendente, ou seja, o educando, só poderá se estabelecer a partir dos movimentos de sua intencionalidade, crítica e reflexão para poder se edificar, e estabelecer a educação não como meio, mas como processo.

Esse é o caráter pedagógico intrínseco aos processos de educação, no qual somente é possível se transformar a partir do diálogo e da compreensão crítica. Para que se possa pensar fora de uma linearidade em que haja um antes e depois, um dentro e fora, um consciente e inconsciente, ou seja, na perspectiva da esperança de um sujeito, que a partir da tomada de consciência ainda não se absolutiza, mas se estabelece e se entende como processo de subjetivação. Esse pode se responsabilizar e se subjetivar de diversas formas, mas sempre se afastando-se da condição de objeto.

Essa esperança de sujeito emerge como uma dobradiça, um entre lugar que não está mais fixo em determinadas possibilidades opostas e reducionistas, e que pode vislumbrar espaços de liberdade, de crítica e de humanização no sentido tradicional da palavra, como autoedificação.

De modo que o conceito de dobradiça é proposto aqui como o entre lugar em que a educação deve se dar, como sua finalidade, não o meio de conduzir daqui para lá, mas como fim, o entre lugar que dá a possibilidade do que fazer do sujeito. O sujeito que quer se fazer para ser mais.

Pensar a educação sob a forma deste entre lugar onde se descortinam os processos de subjetivação implica em diversos deslocamentos das relações pedagógicas conforme estabelecidas pela tradição e que a partir de Freire vão constituir uma codificação pedagógica. Por meio dessa codificação pedagógica, que representa uma reconfiguração dos significados das relações e dos processos educacionais, os educandos precisam ser considerados implicados no e com o mundo em que vivem e devem se desenvolver de forma crítica na construção de um vir a ser mais. A questão pedagógica não pode ser entendida, nem organizada de forma externa e estanque a esses processos de humanização. A obra do autor está alicerçada nessa possibilidade de um sistema de relações em que as práticas pedagógicas precisam ser orientadas e determinadas a partir desta abordagem epistemológica. Os temas geradores, os círculos de cultura, a evolução da consciência ingênua para a consciência crítica, a necessária dialogicidade a aplicação da dialética na construção do conhecimento, e a 
caminhada em direção a libertação através das educações que não podem ser de forma alguma neutras e que são essencialmente políticas representam os alicerces dessa abordagem.

Finalizando, fundamentados no conceito antropológico de cultura, destacamos que Freire abre a possibilidade de se pensar os processos educacionais, a partir de uma concepção de mundo que transcenda a um estar preso a algo dado, fixo, pronto. $\mathrm{O}$ autor possibilita a reflexão de uma educação voltada à compreensão do mundo e do papel dos seres humanos no mundo e com o mundo. Sendo estes responsáveis por repinta-lo, redesenhá-lo e recriá-lo, enquanto partícipes da criação por meio "da transformação e não da adaptação ao mundo".

\section{REFERÊNCIAS}

FREITAS, Ana Lúcia Souza de. Utopia. In: STRECK, Danilo; REDIN, Euclides; ZITKOSKI, Jaime José. (Orgs.). Dicionário Paulo Freire. 2. ed. Belo Horizonte: Autêntica Editora, 2010.

FREIRE, Paulo. Pedagogia da autonomia: saberes necessários à prática educativa. 31 ed. São Paulo: Paz e Terra, 2005.

FREIRE, Paulo. Pedagogia do oprimido. 27. ed. Rio de Janeiro: Paz e Terra Ltda., 1999.

FREIRE, Paulo. Educação como prática da liberdade. Rio de Janeiro: Paz e Terra, 2000. ( $24^{\circ}$ Edição)

FREIRE, Paulo. Ação cultural para a liberdade. Rio de Janeiro: Paz e Terra, 1982.

GHIGGI, Gomercindo. Autoridade. In: STRECK, Danilo; REDIN, Euclides; ZITKOSKI, Jaime José. (Orgs.). Dicionário Paulo Freire. 2. ed. Belo Horizonte: Autêntica Editora, 2010.

HEIDEGGER, M. Ser e tempo: parte II. 2ªed. Trad. Márcia de Sá Cavalcanti. Petrópolis: Vozes, 1998.

MACHADO, Rita de Cássia de Fraga. Autonomia. In: STRECK, Danilo; REDIN, Euclides; ZITKOSKI, Jaime José. (Orgs.). Dicionário Paulo freire. 2. ed. Belo Horizonte: Autêntica Editora, 2010.

ROMÃO, José Estáquio. Ontologia (Freiriana). In: STRECK, Danilo; REDIN, Euclides; ZITKOSKI, Jaime José. (Orgs.). Dicionário Paulo Freire. 2. ed. Belo Horizonte: Autêntica Editora, 2010.

STRECK, Danilo; REDIN, Euclides; ZITKOSKI, Jaime José. (Orgs.). Dicionário Paulo Freire. 2. ed. Belo Horizonte: Autêntica Editora, 2010.

TROMBETTA, Sérgio; TROMBETTA, Luis Carlos. Vocação ontológica. In: STRECK, Danilo; REDIN, Euclides; ZITKOSKI, Jaime José. (Orgs.). Dicionário Paulo Freire. 2. ed. Belo Horizonte: Autêntica Editora, 2010. 
VASCONCELOS, Maria Lucia Marcondes Carvalho; BRITO, Regina Helena Pires de. Conceitos de educação em Paulo Freire: glossário. 6. ed. Petrópolis, RJ: Vozes: São Paulo, SP, 2014.

ZITKOSKI, Jaime José. Humanização / desumanização. In: STRECK, Danilo; REDIN, Euclides; ZITKOSKI, Jaime José. (Orgs.). Dicionário Paulo Freire. 2. ed. Belo Horizonte: Autêntica Editora, 2010.

Recebido: agosto/2018

Aprovado: novembro/2018 